\title{
UNIQUE SOLVABILITY OF FRACTIONAL QUADRATIC NONLINEAR INTEGRAL EQUATIONS
}

\author{
Mohamed Abdalla Darwish* , Mohamed M. A. Metwali \\ AND DONAL O'REGAN
}

Abstract. In this paper we study the existence of monotonic solutions of fractional nonlinear quadratic integral equations in the space of Lebesgue integrable functions on $[0, \tau]$. The uniqueness of the solution is also discussed. In addition an example is given to illustrate our abstract results.

Mathematics subject classification (2010): 45G10, 47H30, 47N20.

Keywords and phrases: Quadratic integral equation, fractional calculus, superposition operator, Darbo fixed point theorem.

\section{REFERENCES}

[1] A. Abdeldaim, On some new Gronwall-Bellman-Ou-Iang type integral inequalities to study certain epidemic models, J. Integral Equations Appl., 24, (2012), 149-166.

[2] J. Appell and P. P. Zabrejko, Nonlinear Superposition Operators, Cambridge Tracts in Mathematics 95, Cambridge University Press, Cambridge, 1990.

[3] N. T. J. BAILEY, The Mathematical Theory of Infectious Diseases and Its Applications, Hafner Press, New York, 1975.

[4] J. Banaś And K. Goebel, Measures of Noncompactness in Banach Spaces, Lect. Notes in Math. 60, M. Dekker, New York-Basel, 1980.

[5] J. BANAŚ AND Z. KNAP, Measures of weak noncompactness and nonlinear integral equations of convolution type, J. Math. Anal. Appl., 146, (1990), 353-362.

[6] A. Bellour, M. Boussels al AND M. AZIZ, Integrable solutions of a nonlinear integral equation related to some epidemic models, Glasnik Matematicki, 49, (2014), 395-406.

[7] M. Cichoń AND M. Metwali, On a fixed point theorem for the product of operators, J. Fixed Point Theory Appl., 18, (2016), 753-770.

[8] M. Cichoń And M. Metwali, Existence of monotonic $L_{\varphi}$-solutions for quadratic Volterra functional-integral equations, Electron. J. Qual. Theory Differ. Equ., 2015, (2015), 1-16.

[9] M. Cichoń AND M. MetwaLi, On monotonic integrable solutions for quadratic functional integral equations, Mediterr. J. Math., 10, (2013), 909-926.

[10] M. Cichoń AND M. Metwali, On the existence of solutions for quadratic integral equations in Orlicz spaces, Math. Slovaca, 66, (2016), 1413-1426.

[11] M. A. DARWISH, Monotonic solutions of a functional integral equation of Urysohn type, PanAmer. Math. J., 18, 4 (2008), 17-28.

[12] M. A. Darwish, J. R. GRAef And K. Sadarangani, On Urysohn-Volterra Fractional Quadratic Integral Equations, J. Appl. Anal. Comput., 8, (2017), 331-343.

[13] M. A. DARWish AND J. Henderson, Solvability of a functional integral equation under Carathéodory conditions, Comm. Appl. Nonlinear Anal., 16, 1 (2009), 23-36.

[14] M. A. DARWISH AND K. SADARANGANI, Nonincreasing solutions of a functional integral equation with Carathéodory perturbed, Mediterr. J. Math., 12, (2015), 63-76.

[15] M. A. DARWish, J. Henderson AND D. O'REgAn, Existence and asymptotic stability of solutions of a perturbed fractional functional-integral equation with linear modification of the argument, Bull. Korean Math. Soc., 48, (2011), 539-553. 
[16] M. A. DARWish And B. SAmET, On Erdélyi-Kober quadratic functional-integral equation in Banach algebra, Numer. Funct. Anal. Optim., 39, (2018), 276-294.

[17] H. Ding, M. LiU, AND J. J. Nieto, Multiple positive solutions for quadratic integral equations of fractional order, J. Funct. Spaces, 2017, Art. ID 4571067, 8 pp.

[18] N. ERzakova, Compactness in measure and measure of noncompactness, Siberian Math. J., 38, (1997), 926-928.

[19] G. Gripenberg, On some epidemic models, Quart. Appl. Math., 39, (1981), 317-327.

[20] G. Gripenberg, Periodic solutions of an epidemic model, J. Math. Biol., 10, (1980), 271-280.

[21] M. A. Krasnosel'skit, P. P. Zabrejko, E. I. Pustylnik and P. E. Sobolevskit, Integral Operators in Spaces of Summable Functions, Nauka, Moscow, 1966 (English translation: Noordhoff, Leyden, 1976).

[22] J. KRZYŻ, On monotonicity-preserving transformations, Ann. UMCS, 6, (1952), 91-111.

[23] K. S. Miller And B. Ross, An Introduction to Fractional Calculus and Fractional Differential Equations, John Wiley and Sons, New York 1993.

[24] M. Metwali, On a class of quadratic Urysohn-Hammerstein integral equations of mixed type and initial value problem of fractional order, Mediterr. J. Math., 13, (2016), 2691-2707.

[25] M. Metwali, On some qualitative properties of integrable solutions for Cauchy-type problem of fractional order, J. Math. Appl., 40, (2017), 121-134.

[26] M. Metwali, Solvability of functional quadratic integral equations with perturbation, Opuscula Math., 33, (2013), 725-739.

[27] I. M. OLARU, Generalization of an integral equation related to some epidemic models, Carpathian J. Math., 26 (2010), 92-96.

[28] B. G. PaChPatTe, On a new inequality suggested by the study of certain epidemic models, J. Math. Anal. Appl., 195, (1995), 638-644.

[29] L. Li, F. MENG AND P. JU, Some new integral inequalities and their applications in studying the stability of nonlinear integro-differential equations with time delay, J. Math. Anal. Appl., 377, (2011), 853-862.

[30] M. V̈̈тH, Volterra and Integral Equations of Vector Functions, Marcel Dekker, New York-Basel, 2000. 